ARTIGO

DE REVISÃO

\title{
Transição caminhada-corrida: considerações fisiológicas e perspectivas para estudos futuros
}

\author{
Walace David Monteiro ${ }^{1,2}$ e Claudio Gil Soares de Araújo ${ }^{1,3}$
}

\section{RESUMO}

Freqüentemente, os profissionais que atuam na atividade física deparam-se com um dos seguintes questionamentos: Qual a melhor atividade, caminhar ou correr? Quando devo parar de caminhar e começar a correr? Seria interessante alternar as duas formas de atividade? Se, por um lado, as perguntas podem ser facilmente respondidas para um indivíduo saudável e bem condicionado, para os demais permanecem dúvidas que devem ser esclarecidas. Enquanto andar e correr são mais eficientes em velocidades, respectivamente, abaixo de $6 \mathrm{~km} . \mathrm{h}^{-1}$ e acima de $8 \mathrm{~km} \cdot \mathrm{h}^{-1}$, permanece indefinida qual a melhor forma de locomoção na faixa intermediária de velocidade, ou seja, na intensidade de esforço em que ocorre a transição entre a caminhada e a corrida. É nesse ponto que recaem dúvidas sobre os mecanismos fisiológicos que regulam a seleção da locomoção. Além disso, também permanecem sem explicações convincentes quais as implicações que os diferentes modos de locomoção podem exercer sobre as variáveis que caracterizam a intensidade de esforço. Dessa forma, este artigo objetiva revisar os estudos que abordam os mecanismos envolvidos na transição caminhada-corrida, apontando lacunas que possam ser objeto de pesquisas acerca dos mecanismos e implicações das respostas fisiológicas obtidas nessa faixa de esforço. O texto foi organizado com os seguintes tópicos: estudo da locomoção humana através de

1. Programa de Pós-Graduação em Educação Física - UGF, Rio de Janeiro, RJ.

2. Laboratório de Fisiologia do Exercício - Nuicaf/Aeronáutica, Rio de Janeiro, RJ.

3. Clínica de Medicina do Exercício - Clinimex, Rio de Janeiro, RJ.

Recebido em: 16/5/01

Aceito em: 24/7/01

Endereço para correspondência:

Claudio Gil Soares de Araújo

Clínica de Medicina do Exercício - Clinimex

Rua Siqueira Campos, 93/102

22031-070 - Rio de Janeiro, RJ

E-mail:cgaraujo@iis.com.br modelos matemáticos; protocolos utilizados nos estudos de transição caminhada-corrida; aspectos metabólicos do trabalho em esteira e no solo; características antropométricas e transição caminhada-corrida; demanda energética e transição caminhada-corrida; estabilidade locomotora e transição caminhada-corrida. Em todos, realizou-se um comentário de seus pontos positivos, controvérsias e limitações. Por fim, são apontadas algumas possibilidades que poderiam ser alvo de investigações futuras.

Palavras-chave: Locomoção humana. Transição caminhada-corrida. Economia de corrida. Consumo de oxigênio. Fisiologia do exercício. Condicionamento físico.

\section{ABSTRACT \\ Walking-running transition: physiological considerations and perspectives for future studies}

Professionals who deal with physical activity are frequently confronted with one of the following questions: which is the best activity, walking or running? When should I stop walking and start running? Would it be interesting to alternate the two types of activity? Although these questions can be easily answered for a healthy and fit individual, some doubts remain and need to be clarified for other cases. While walking and running are more efficient in velocities below $6 \mathrm{~km} \cdot \mathrm{h}^{-1}$ and above $8 \mathrm{~km} . \mathrm{h}^{-1}$, respectively, the best way of locomotion in the intermediate zone, that is, when effort intensity is increased in the transition from walking to running, is still unknown. At this point there are some doubts regarding the physiological mechanisms that regulate the locomotion selection. In addition, there is no clear explanation about the implications of the different types of locomotion on the variables that characterize exercise intensity. This article focus around the following topics: study of human locomotion through mathematical models; protocols used in walking-running transition studies; metabolic aspects of the work on a treadmill and on the ground; anthropometric characteristics and walkingrunning transition; energetic demand and walking-running transitions; motor stability and walking-running transition. 
In all of them, the positive aspects, as well as the controversies and limitations, were discussed. Finally, the authors point out to some possibilities for future investigations.

Key words: Human locomotion. Walking-running transition. Running economy. Oxygen uptake. Exercise physiology. Physical conditioning.

\section{INTRODUÇÃO}

O interesse na fisiologia do exercício tem aumentado nas últimas décadas. As razões para isso, talvez, envolvam a publicação e divulgação de estudos científicos em número cada vez maior de revistas científicas especializadas. Outro aspecto diz respeito ao crescimento do interesse acerca do exercício associado à promoção da saúde, fato traduzido pelo grande número de pesquisas de cunho experimental e epidemiológico publicadas nas últimas décadas. Podese, ainda, destacar a redução dos custos do instrumental destinado à coleta e análise de dados, bem como a grande disseminação dos laboratórios de fisiologia do exercício em universidades, entidades desportivas, centros de saúde e clínicas especializadas.

Dentre os vários conteúdos referentes à fisiologia do exercício, aqueles relacionados à demanda energética e às respostas ventilatórias ao esforço têm despertado especial atenção dos pesquisadores. Talvez isso ocorra devido à sua aplicabilidade em diversos campos do conhecimento, como nos estudos relacionados à aptidão física, ao desempenho atlético, à capacitação para o trabalho e à saúde. Mas, ainda que se possa afirmar que essa área específica da fisiologia venha sendo exaustivamente estudada, muitas dúvidas ainda necessitam ser elucidadas.

$\mathrm{O}$ desempenho de atividades motoras diversificadas, ou mesmo das mesmas tarefas em distintos indivíduos, pode requerer demandas metabólicas diferentes, implicando graus de sobrecargas diferenciados nos sistemas que compõem o corpo humano, marcadamente o muscular e o cardiorrespiratório. Dessa forma, a interpretação das oscilações metabólicas constitui um importante elemento na análise das implicações acerca dos efeitos fisiológicos em diferentes manifestações de esforço. Em se tratando do desempenho motor, parece ser consenso que a quantidade total de energia despendida por um indivíduo depende de aspectos como as dimensões corporais, a termogênese induzida pelos alimentos e a atividade física ${ }^{1}$. Entretanto, é a atividade física que tende a influenciar mais profundamente o dispêndio de energia. Essa informação torna-se especialmente importante ao relacionarmos os efeitos do exercício a situações diversas, como, por exemplo, o dimensionamento da intensidade do esforço em diferentes atividades motoras.
O estudo da demanda metabólica nas atividades físicas pode ser realizado de forma indireta através da análise de gases expirados. Dentre as principais variáveis ventilatórias fornecidas por essa técnica, podemos destacar o consumo de oxigênio $\left(\dot{\mathrm{V}}_{2}\right)$, a ventilação pulmonar (VE), a produção de gás carbônico $\left(\mathrm{VCO}_{2}\right)$, o pulso de oxigênio (pulso de $\mathrm{O}_{2}$ ), os equivalentes ventilatórios de oxigênio $\left(\mathrm{VE} / \mathrm{V}_{2}\right)$ e de gás carbônico $\left(\mathrm{VE} / \mathrm{VCO}_{2}\right)$ e o quociente de troca respiratória $(\mathrm{QR})^{2}$. A interpretação conjunta dessas variáveis fornece informações precisas sobre uma série de mecanismos envolvidos no controle da função cardiorrespiratória, em repouso e durante determinada atividade.

Embora o emprego da análise de gases expirados favoreça o cálculo da demanda metabólica com razoável exatidão em algumas atividades ${ }^{3}$, persistem lacunas na literatura. Em particular, desperta-nos interesse o estudo dos mecanismos fisiológicos que determinam a transição caminhada-corrida. Um melhor entendimento desses mecanismos pode ser relevante para a prescrição e o controle do treinamento, principalmente para aqueles praticantes cuja faixa de intensidade ótima de treinamento situa-se acima do caminhar e abaixo do correr.

Frequientemente, os profissionais que atuam na atividade física deparam com um dos seguintes questionamentos: Qual a melhor atividade, caminhar ou correr? Quando devo parar de caminhar e começar a correr? Seria interessante alternar as duas formas de atividade? Se, por um lado, as perguntas podem ser facilmente respondidas para um indivíduo saudável e muito bem condicionado, para os demais permanecem dúvidas que devem ser esclarecidas. Vejamos uma colocação que justifica tal afirmativa. Do ponto de vista estritamente físico, o trabalho para percorrer determinada distância independe do modo de locomoção (caminhar ou correr). Contudo, é possível que a demanda metabólica efetiva possa diferir na mesma velocidade entre essas duas modalidades de locomoção. Além disso, sabese há algum tempo que parecem existir velocidades em que o andar é mais vantajoso do que o correr em termos de eficiência mecânica e vice-versa ${ }^{4}$. Segundo o American College of Sports Medicine ${ }^{5}$, andar e correr são mais eficientes em velocidades, respectivamente, abaixo de $6 \mathrm{~km} \cdot \mathrm{h}^{-1} \mathrm{e}$ acima de $8 \mathrm{~km} \cdot \mathrm{h}^{-1}$, permanecendo, todavia, indefinida a melhor forma de locomoção na faixa intermediária de velocidade, ou seja, na intensidade de esforço em que ocorre a transição entre a caminhada e a corrida. Analisando esse aspecto, Hanna et al. ${ }^{6}$ destacam que ainda não estão claros quais os mecanismos que o sistema motor humano utiliza para controle e/ou otimização da demanda energética, nas intensidades de esforço de transição entre a caminhada e a corrida. Além disso, também permanecem sem explicações convincentes quais as implicações que os diferentes mo- 
dos de locomoção podem ter sobre as variáveis que caracterizam a intensidade de esforço, na faixa de transição caminhada-corrida.

Uma das teorias mais aceitas pelos pesquisadores é a de que as mudanças na forma de locomoção aparecem como uma tentativa de minimizar o gasto energético ${ }^{6-21}$. Contudo, vários elementos têm o potencial de influenciar na velocidade de transição. Algumas considerações metodológicas-chaves incluem a forma pela qual a velocidade de locomoção está sendo manipulada (adoção de protocolos em rampa ou escada), a direção na qual a velocidade está sendo aumentada ou reduzida e se a manipulação ocorre usando a locomoção sobre o solo ou esteira. Pode-se, ainda, acrescentar a influência das dimensões corporais, o efeito da idade ou mesmo as diferenças na composição corporal.

Em recente revisão sobre os mecanismos de transição entre a caminhada e a corrida, Patla e Sparrow ${ }^{22}$ concluí- $^{-}$ ram que múltiplos objetivos são otimizados durante a locomoção. Nesse caso, a proposição da minimização da demanda metabólica de energia como único critério de otimização do passo humano pode ser uma simplificação exagerada do fenômeno. Além disso, não se sabe a extensão das variáveis que podem influenciar na escolha da forma de locomoção, bem como o percentual de contribuição de cada fator no processo de transição.

Assim, este artigo objetiva revisar os estudos que abordam os mecanismos envolvidos na transição caminhadacorrida, apontando algumas lacunas que possam ser objeto de pesquisas adicionais para melhor entendimento dos mecanismos e implicações das respostas fisiológicas obtidas nessa faixa de esforço. A revisão da literatura envolveu pesquisa no Medline, utilização de referências cruzadas e de capítulos de livros específicos sobre o tema em questão. $\mathrm{O}$ texto foi organizado em sete tópicos, comentando seus pontos positivos e limitações. Por fim, são apontadas algumas possibilidades que poderiam ser alvo de investigações futuras.

\section{ESTUDO DA LOCOMOÇÃO HUMANA ATRAVÉS DE MODELOS MATEMÁTICOS}

A locomoção humana é caracterizada pelos atos de andar e correr, utilizados para os deslocamentos em baixa e alta velocidade, respectivamente. Em baixas velocidades, a caminhada pode ser acelerada aumentando a freqüência ou o comprimento das passadas. Na maior parte das velocidades que caracterizam essa forma de locomoção, existe uma relação linear entre o comprimento e a freqüência dos passos $^{23,24}$, apesar de, em altas velocidades, o limite máximo do comprimento dos passos ser atingido primeiro ${ }^{25}$.
Conforme aumentamos a intensidade do esforço, atingimos uma velocidade crítica a partir da qual passamos a correr. Essa modificação no padrão de movimento caracteriza a transição caminhada-corrida, que tem sido estudada através de várias abordagens, com o objetivo de buscar maior entendimento do fenômeno. Uma delas é a caracterização biomecânica da locomoção, realizada através de modelos matemáticos. Embora o objetivo do presente texto não seja um aprofundamento na caracterização matemática da transição caminhada-corrida, não se pode excluir a importância desse aspecto no estudo do fenômeno.

Pode-se dizer que o ato de correr é tipicamente modelado como um sistema bouncing ball, em contraste com o ato de caminhar, modelado como rolling egg ${ }^{4,6,26}$. No primeiro, observam-se elevadas trocas de energia cinética e elástica, sendo esta última, possivelmente, gerada pela energia armazenada nos tendões e músculos dos membros em contato com o solo. Já no segundo, a troca de energia ocorre de maneira mais suave.

Vários modelos matemáticos têm sido desenvolvidos para o estudo da locomoção humana ${ }^{16,27-34}$. Andar tem sido descrito como um sistema de pêndulo invertido, com trocas conservativas de energia cinética e potencial. Exemplificando tal transformação, pode-se dizer que, dentro da coordenação do andar, o centro de massa perde velocidade (energia cinética) ao ganhar altura (energia potencial), ocorrendo o mesmo no processo reverso. Já o ato de correr, como dito, é modelado como um sistema bouncing ball, com elevadas trocas de energia cinética e elástica. Uma importante diferença entre os dois modelos reside na forma pela qual a troca de energia é realizada. Nesse caso, a troca ocorre de maneira mais suave no modelo de pêndulo invertido que caracteriza a caminhada ${ }^{6}$.

Esses modelos têm provado ser quase precisos em predizer a frequiência e amplitude dos passos, os duty factors e os padrões da força de reação vertical do solo, tanto para o andar quanto para o correr. Todavia, seus maiores defeitos têm sido relacionados como o fracasso em predizer, com precisão, a velocidade de locomoção no ponto de transição entre as formas de locomoção ${ }^{27,28,35}$. Esses modelos predizem que a transição entre os modos de locomover-se pode ocorrer no limite mecânico do sistema físico. Modelos baseados no sistema de pêndulo invertido, como o apresentado por $\mathrm{McGeer}^{31}$, assumem que o centro de massa do corpo descreve um arco ao redor de uma perna rígida de raio L. A aceleração tangencial do centro de massa em direção ao pé é igual à velocidade $2 / L$. Para que o pé permaneça em contato com o solo durante a fase de ondulação do membro contralateral, o valor da aceleração tangencial não pode exceder a aceleração da gravidade. Daí, é prová- 
vel que a transição entre o andar e o correr ocorra no ponto onde a aceleração do centro de gravidade do corpo em direção ao chão excede a aceleração da gravidade. Isto é, a transição ocorre quando: velocidade > ( $\mathrm{g}$ x comprimento da perna $)^{0,5}$. Quando essa velocidade de locomoção é atingida, o pé não consegue permanecer em contato com o solo, resultando numa fase de vôo, caracterizando a corrida. Entretanto, esse modelo pode ser criticado. Diedrich e Warren $^{36}$, por exemplo, salientam que, ao substituírem-se os comprimentos de uma perna entre $0,8 \mathrm{~m}$ e $0,9 \mathrm{~m}$ no modelo, a velocidade de transição preferida calculada é de aproximadamente $3 \mathrm{~m} \cdot \mathrm{s}^{-1}$, o que foi demonstrado ser excessivo através de métodos experimentais.

A dificuldade com o modelo tradicional, na qual se trata o andar e o correr como um sistema discreto com conservação de energia (energia do andar sendo convertida através de ações em forma de pêndulo e a energia da corrida através de ações de mola), é que modelos de coordenação contêm elementos de ambos os métodos de conservação de energia. Como conseqüência, modelos híbridos que apresentam ambos os componentes pendular e de elasticidade (inercial e elástico) podem oferecer maior potencial na determinação de características biomecânicas de cada modo de locomover-se e da transições entre eles - esse é o caso do modelo de Holt et al. ${ }^{17,37}$, apropriado para decifrar um número-chave de fenômenos típicos da marcha, especialmente aqueles relacionados à caminhada. Contudo, embora o modelo acrescente alguns conceitos que podem ser incorporados aos modelos de locomoção anteriores, não está claro se o melhor entendimento sobre a preferência entre o andar e o correr irá necessariamente traduzir-se em melhor compreensão do fenômeno de transição entre as duas formas de locomoção ${ }^{6}$.

Para finalizar esta sessão, destacamos que os modelos matemáticos podem ser extremamente úteis ao entendimento de determinado processo. Contudo, os mesmos não são completos para descrevê-lo, já que é difícil obter modelos perfeitos, principalmente quando aplicados aos seres humanos. De fato, verifica-se falta de consenso quanto ao modelo que mais se ajustaria tanto à caminhada quanto à corrida. Além disso (e destacamos a importância dessa constatação na presente revisão), não pudemos localizar na literatura modelos que procurassem explicar, especificamente, o processo de transição caminhada-corrida. Estudos nessa linha são, portanto, escassos, representando uma lacuna que deveria ser explorada pelos pesquisadores.

\section{PROTOCOLOS UTILIZADOS NOS ESTUDOS DE TRANSIÇÃO CAMINHADA-CORRIDA}

A diferenciação do momento ou intensidade do esforço a partir do qual ocorre a transição caminhada-corrida pas- sa, inicialmente, pela característica específica do protocolo adotado. Uma das formas de diferenciar o caminhar do correr consiste na determinação da fração de duração da passada em que cada pé permanece no chão. Esse fenômeno tem sido chamado de duty factor. Alexander ${ }^{28}$ destaca que no momento em que o duty factor é maior do que 0,5, a pessoa desempenha a ação de caminhar. Em contrapartida, quando o mesmo é menor do que 0,5 , teríamos como resultado a fase de vôo, evidenciando a corrida. Até a obtenção de velocidade próxima a $2 \mathrm{~m} \cdot \mathrm{s}^{-1}$, o modo de locomoção geralmente é sustentado pelo ato de caminhar. Após essa velocidade, ocorreria uma modificação na organização do movimento, resultando na corrida. Essa reorganização, decorrente da introdução da fase de vôo, ocorre pelo aumento da força propulsiva no chão. A identificação dessa velocidade como ponto aproximado na qual a transição caminhada-corrida ocorreria tem sido descrita em vários estudos ${ }^{18,19,38-42}$. Contudo, quando é necessário identificar com exatidão o momento em que ocorre a mudança no padrão de movimento, a escolha dos protocolos pode desempenhar um papel de suma importância, pois os resultados parecem ser protocolo-dependentes. Nesse caso, uma correta arquitetura do protocolo representa o primeiro passo para uma coleta de dados fidedigna.

Quando se deseja estudar as respostas fisiológicas em testes padronizados, uma importante característica a ser considerada diz respeito à forma pela qual as cargas de esforço são manipuladas. Talvez, essa seja a característica mais importante de um protocolo, visto que cargas aplicadas de forma inadequada podem mascarar os resultados. Um protocolo pode envolver várias características. Araú$\mathrm{jo}^{43}$, discorrendo sobre esse assunto, assinala que todos os protocolos apresentam virtudes e defeitos, sendo os objetivos do teste a característica da população testada, a disponibilidade de tempo e de material que decidirão a melhor escolha. Esse autor destaca que existem basicamente cinco características de um protocolo de teste de esforço, a saber: a) quanto ao grau de esforço envolvido - teste máximo: quando o indivíduo é levado à exaustão voluntária máxima ou o teste é interrompido devido a sinais e sintomas clínicos importantes; teste submáximo: no qual são considerados todos os outros protocolos que não se enquadram na característica anterior; como exemplo podemos citar aqueles que são interrompidos após um tempo predeterminado de esforço ou pela obtenção de uma freqüência cardíaca ou carga alvo; b) quanto ao tipo de esforço envolvido - teste estático: envolve contração muscular estática, em que praticamente não existe movimento; um exemplo típico dessa forma de teste é a dinamometria manual; teste dinâmico: envolve contração dinâmica, geralmente realizado em esteira, bicicleta, banco ou pista; c) quanto ao 
número de cargas - única carga: aquele que envolve um único grau de esforço, sendo menos utilizado em função da menor discriminação fisiológica; duas ou mais cargas: composto por um número variado de cargas, determinadas em função do objetivo do teste ou da capacidade do praticante em permanecer no protocolo; d) quanto à duração dos estágios - com steady-state: apresentam tempo suficiente para o organismo ajustar-se à demanda da carga; sem steady-state: não apresentam tempo para o organismo adequar-se à demanda da carga; com relação a essa característica do protocolo, chamamos atenção para a importância do tempo em cada estágio e suas possibilidades de discriminação das respostas objetivadas; e) quanto à presença e ausência de pausas - teste contínuo: caracteriza-se pela ausência de pausas; teste descontínuo: composto por intervalos que caracterizam níveis de repousos ativos (esforços leves entre as cargas) ou passivos (sem esforços entre as cargas).

Outra característica importante na arquitetura de um protocolo diz respeito à razão em que as cargas serão aplicadas. Nesse caso, os testes podem ser executados em rampa ou escada. Protocolos em rampa caracterizam-se por apresentar incrementos ou reduções na intensidade de esforço de forma constante. Já os protocolos em escada envolvem a manipulação da intensidade do esforço em discretos incrementos ou reduções, em que o período destinado a cada estágio geralmente é constante.

No que toca aos estudos de transição entre a caminhada e a corrida, embora não exista uma opinião consensual na literatura, parece ser aceito que, quando aplicados com incremento de velocidades de $0,3 \mathrm{~km} . \mathrm{h}^{-1}$, os protocolos em escada parecem ser mais consistentes em termos de confiabilidade do que os protocolos de rampa ${ }^{44}$. No entanto, em relação ao aumento da velocidade, as limitações das esteiras adotadas em algumas investigações dificultam o controle preciso do ponto no qual as condições de velocidade adjacente mudam. A esteira aceleraria muito mais rapidamente em altas do que em baixas velocidades e durante subidas ao invés de descidas. Esse problema metodológico pode tornar-se uma preocupação particular durante testes em subida, em que a escala de mudança de velocidade pode ser um importante estímulo para a transição ${ }^{6}$. É importante estar consciente desse problema, pois a variabilidade da escala de mudança requerida do passo pode confundir uma simples comparação da eficácia de diferentes protocolos de manipulação da velocidade.

Uma estratégia interessante, normalmente não utilizada nos estudos que investigam o processo de transição caminhada-corrida, é a validação do protocolo antes de sua aplicação no estudo propriamente dito. Nesse caso, diferentes razões de incrementos e distintos tempos de estágios de- vem ser testados para estabelecer o protocolo específico. Com esse intuito, uma proposta interessante poderia consistir na verificação da confiabilidade dos resultados em protocolos com duração de cinco a 30 segundos, variando o incremento de carga na ordem de 0,1 a $0,5 \mathrm{~km} \cdot \mathrm{h}^{-1}$. A partir do conhecimento das influências da aplicação das cargas de esforço na velocidade de transição em determinada amostra, o procedimento seria, então, utilizado no estudo.

\section{ASPECTOS METABÓLICOS DO TRABALHO EM ESTEIRA E NO SOLO}

Uma dúvida que freqüentemente surge ao compararmos trabalhos realizados em esteira e no solo diz respeito à extrapolação dos dados de uma situação para a outra. Algumas evidências sugerem que correr na esteira não muda a energia requerida para a locomoção, quando comparada com a obtida no solo ${ }^{45-47}$. Apesar disso, é aceito que a variabilidade das respostas metabólicas seja menor em estei$\mathrm{ra}^{48}$, provavelmente devido ao controle das condições ambientais em situações laboratoriais, fato nem sempre possível ao ar livre.

Bassett et $a l .^{45}$, em estudo comparativo do consumo de oxigênio obtido na corrida em superfície plana e em subida, reportaram que a demanda de oxigênio na esteira e no solo foi similar para velocidades entre 136 e $286 \mathrm{~m} \cdot \mathrm{min}^{-1}$. Em concordância com esses dados, McMiken e Daniels ${ }^{47}$ também não encontraram diferenças significativas na corrida em esteira e no solo, quando realizada numa faixa de velocidade de 180 a $260 \mathrm{~m} \cdot \mathrm{min}^{-1}$. Entretanto, essa evidência está longe de ser considerada uma verdade absoluta, principalmente ao considerar-se uma faixa mais elevada de esforço. De fato, em altas velocidades de corrida, diferenças no gasto energético, na largura da passada e em certos parâmetros temporais são evidentes ${ }^{49-51}$. Frishberg ${ }^{52}$, por exemplo, demonstrou diferenças substanciais no gasto energético no solo e na esteira. Tais diferenças ocorrem porque corridas rápidas envolvem movimentação muito mais ativa da perna de apoio que outras formas menos intensas de correr, por exemplo, o jogging. Isso pode ocasionar modificações importantes na mecânica do movimento, alterando a quantidade de massa muscular envolvida e afetando a demanda energética. Outros fatores podem ainda ser adicionados. Entre eles, pode-se citar a resistência gerada pelo vento, a dificuldade associada à corrida na esteira e uma possível variação na velocidade da esteira a partir do toque de cada pé do indivíduo no tapete ${ }^{12,48,51,53}$.

O fracasso de alguns estudos para mostrar a completa similaridade entre correr no solo e na esteira pode ser devido às diferenças entre as duas condições de andar existentes para alguns, mas não para todos os indivíduos. Com 
respeito a esse assunto, Nigg et al. ${ }^{54}$, investigando a cinemática de corrida na esteira e no solo, verificaram que as diferenças medidas nas variáveis cinemáticas podem ser subdivididas em sistemáticas e sujeito-dependentes. Segundo os autores, na esteira os sujeitos adaptam o seu estilo de aterrissagem para que o pé aterrisse em posição mais reta do que durante a corrida no chão. Essa estratégia pode promover um toque do pé na esteira, que é percebido pelos corredores como mais estável do que no solo. Além disso, quase todas as variáveis cinemáticas da parte inferior da perna mostraram um padrão inconsistente, dependendo do estilo de aterrissagem individual do atleta, da velocidade da corrida e da situação do calçado em relação à esteira. Concluiu-se que a extrapolação dos resultados cinemáticos da corrida na esteira para a corrida no chão depende de aspectos como padrão não sistemático requerido na esteira, a velocidade de corrida e o tipo específico de calçado usado.

Como destacado por Hanna et $a .^{6}{ }^{6}$, as pesquisas passadas tenderam a usar testes estatísticos para determinar se existiam diferenças entre os grupos que andavam na esteira e no solo, as variações individuais tendo sido ignoradas. Isso pode apresentar um significado importante ao transportarmos os dados laboratoriais para situações de campo. Nesse caso, não é possível determinar se os constrangimentos impostos pelas duas condições são os mesmos na maioria das pessoas. Todavia, o aspecto mais importante em relação à investigação do fenômeno de transição não é se uma mesma velocidade crítica de locomoção define a transição caminhada-corrida na esteira, comparada com a locomoção no solo, mas se as mesmas características tipificam a transição dentro de cada estilo.

Em se tratando dos estudos na faixa de esforço em que ocorre a transição caminhada-corrida, e até mesmo um pouco acima desta, as evidências sugerem que os dados obtidos em esteira podem ser transportados para as situações de campo. Isso é válido até a obtenção de velocidades em torno de 260-280m. $\mathrm{min}^{-1}$, em que os valores de consumo de oxigênio não se diferenciam significativamente entre as duas situações. Todavia, mediante as dificuldades de alguns praticantes para locomover-se na esteira, bem como as diferenças mais acentuadas nas condições ambientais e de terreno, a transposição dos dados deve ser feita com cautela e, preferencialmente, após alguma fase de adaptação à locomoção em esteira rolante.

\section{CARACTERÍSTICAS ANTROPOMÉTRICAS E TRANSIÇÃO CAMINHADA-CORRIDA}

Ao analisarmos os possíveis responsáveis pela modificação na forma de locomoção com o aumento da intensidade do esforço, é racional sugerir que um ou mais parâ- metros físicos ligados às dimensões corporais possam ser responsáveis por disparar o gatilho de transição entre a caminhada e a corrida. Vejamos, a seguir, algumas evidências da possível ligação entre a variação antropométrica humana e suas relações com a velocidade de transição.

É sensato pensar que a relação entre as características corporais e o desempenho em determinada tarefa motora passa, inicialmente, pela natureza da atividade. No que concerne à corrida, a variação da velocidade constitui um importante fator a ser considerado. Brisswalter et al..$^{55}$ realizaram um estudo com o propósito de inter-relacionar o comprimento da passada, a economia da corrida e as medidas antropométricas em corredores de elite. Para tanto, utilizaram duas velocidades de corrida: uma submáxima, próxima da usual de treinamento $\left(15 \mathrm{~km} \cdot \mathrm{h}^{-1}\right)$ e uma não usual $\left(9 \mathrm{~km} \cdot \mathrm{h}^{-1}\right)$, próxima da velocidade de transição entre o andar e o correr. A economia da corrida foi expressa em $\mathrm{ml} \cdot \mathrm{kg}^{-1} \cdot \mathrm{min}^{-1} \mathrm{e}$ em ml. $\mathrm{kg}^{-0,75} \cdot \mathrm{min}^{-1}$. Além disso, para comparar diferentes velocidades, o gasto energético foi expresso em unidade de distância. Nove variáveis antropométricas foram medidas: massa corporal, gordura corporal (seis dobras), estatura, altura sentado, altura de membros inferiores (altura total - altura sentada), comprimento de membros inferiores, comprimentos tibial e da coxa e comprimento dos pés.

Para as duas velocidades de corrida, a influência das dimensões corporais na economia de corrida foi diferente. A $9 \mathrm{~km} \cdot \mathrm{h}^{-1}$, a massa corporal representou a mais importante variável em uma regressão múltipla. Enquanto isso, a $15 \mathrm{~km} \cdot \mathrm{h}^{-1}$, os melhores preditores da economia de corrida foram o comprimento da perna e a estatura. Quando a regressão linear foi usada, observou-se relação inversa entre as dimensões corporais e a economia de corrida para as duas velocidades e um efeito do modo de expressar o $\dot{\mathrm{V}}_{2}$. A $9 \mathrm{~km} \cdot \mathrm{h}^{-1}$, não foi evidenciada correlação significativa entre a economia de corrida em $\mathrm{ml} \cdot \mathrm{kg}^{-1} \cdot \mathrm{min}^{-1} \mathrm{e}$ as dimensões corporais. No entanto, quando o $\mathrm{V}_{2}$ era expresso em ml. $\mathrm{kg}^{-0,75} \cdot \mathrm{min}^{-1}$ (para minimizar a influência da massa corporal), o mesmo foi significativamente e positivamente correlacionado com a altura, massa corporal, comprimento da coxa e gordura corporal. Em contraste, a $15 \mathrm{~km} \cdot \mathrm{h}^{-1}$, o $\dot{\mathrm{V}}_{2}$ expresso em ml. $\mathrm{kg}^{-1} \cdot \mathrm{min}^{-1}$ ou em ml. $\mathrm{kg}^{-0,75} \cdot \mathrm{min}^{-1}$ foi significativamente e negativamente correlacionado com a massa corporal, altura e comprimento da perna, e positivamente associado com o percentual de gordura. Além do mais, nenhuma correlação significativa foi encontrada entre o gasto energético a 9 e a $15 \mathrm{~km} \cdot \mathrm{h}^{-1}$.

No tocante às dimensões corporais, apenas a estatura e o comprimento das pernas mostraram relação significativa com o $\dot{\mathrm{V}}_{2}$ e somente a estatura se relacionou com o comprimento do passo. Para todas as velocidades, a estatura correlacionou-se positivamente com o comprimento do 
passo. Além disso, nenhuma correlação significativa foi verificada entre o comprimento do passo e as dimensões da perna. Uma suposição feita por Alexander ${ }^{35}$, de que o comprimento do passo é melhor descrito pela função alométrica do que pela função linear, pode explicar esse resultado. A frequiência de passos preferida representa variáveis globais, que não podem ser descritas com variáveis locais, por uma função linear, como, por exemplo, o comprimento da perna. Uma relação inversa, mas significativa, foi observada entre a estatura, comprimento da perna e economia de corrida para as duas velocidades de corrida. A $9 \mathrm{~km}$, quando o $\mathrm{V}_{2}$ está expresso em $\mathrm{ml} \cdot \mathrm{kg}^{-1} \cdot \mathrm{min}^{-1}$, nenhuma correlação foi observada entre as duas variáveis. Quando o $\mathrm{VO}_{2}$ foi expresso em ml. $\mathrm{kg}^{-0,75} \cdot \mathrm{kg}^{-1}$, uma relação positiva foi vista. Dessa forma, o modo de expressão para minimizar a importância do peso corporal permitiu observar a relação significativa entre dimensões corporais e economia da corrida. Em conclusão, verificou-se um efeito dependente da velocidade da corrida na relação entre dimensões corporais, comprimento dos passos e $\dot{\mathrm{VO}}_{2}$. Por outro lado, nenhuma relação foi encontrada entre o custo energético a 9 e a $15 \mathrm{~km} . \mathrm{h}^{-1}$ e relação inversa foi observada entre as dimensões corporais e o $\dot{\mathrm{VO}}_{2}$ para as duas velocidades de corrida. Além disso, o modo de expressar o $\dot{\mathrm{V}}_{2}$ tende a afetar essa relação.

Para analisar se a relação com a velocidade de transição era influenciada pela magnitude da aceleração, desaceleração ou pelas dimensões do indivíduo, Thorstensson e Roberthson ${ }^{56}$ conduziram um estudo envolvendo 18 homens saudáveis, divididos em três grupos, de acordo com o comprimento da perna, a saber: pequena $(0,86$ a $0,91 \mathrm{~m})$, média $(0,93$ a $0,95 \mathrm{~m})$ e longa $(1,03$ a $1,09 \mathrm{~m})$. A locomoção foi executada numa esteira, acelerada e desacelerada em velocidades entre 1,0 e $3,0 \mathrm{~m} \cdot \mathrm{s}^{-1}$. A velocidade foi monitorizada por um velocímetro e sua variação foi aplicada através de três diferentes magnitudes: $0,05,0,08 \mathrm{e} 0,11 \mathrm{~m} \cdot \mathrm{s}^{-1}$ (o tempo de mudança entre 1,0 e $3,0 \mathrm{~m} \cdot \mathrm{s}^{-1}$ foi de 40,25 e 18 segundos, respectivamente). $\mathrm{O}$ modo de locomoção normal a $1,0 \mathrm{~m} \cdot \mathrm{s}^{-1}$ era o andar, enquanto o correr foi desenvolvido a $3 \mathrm{~m} . \mathrm{s}^{-1}$. Logo, as variações de velocidades selecionadas incluíram a velocidade de transição natural entre o andar e o correr. Como resultado, o grupo com pernas mais curtas mostrou velocidade de transição mais baixa que os outros, enquanto nenhuma diferença foi encontrada para os grupos com pernas médias e longas. Em todo o estudo, verificou-se fraca tendência em direção ao aumento da velocidade na qual a transição foi obtida e o aumento do comprimento da perna, apesar de a variação dentro de cada grupo ter sido relativamente ampla, revelando um comportamento individual muito variável dentro de cada faixa de comprimento de perna estudada.
Em outro estudo digno de nota, Hreljac ${ }^{42}$ correlacionou os valores médios da velocidade de transição preferida em 28 participantes de ambos os sexos com uma série de variáveis antropométricas que incluíram: massa corporal, estatura, altura do maléolo lateral, comprimento de membros inferiores, altura da crista ilíaca anterior, comprimento da coxa, comprimento da coxa dividido pela altura sentada e o número Froude ${ }^{1}$. O estudo evidenciou moderadas correlações $(r=0,57)$ entre os valores da velocidade preferida e das variáveis antropométricas. Níveis relativamente baixos de associação também foram verificados por Getchell e Whitall ${ }^{57}$. Esses autores usaram a técnica de regressão múltipla passo a passo para tentar achar variáveis físicas que pudessem prever a transição do andar-correr, correrandar, bem como da transição para o trotar. Dez medidas antropométricas foram examinadas (massa corporal, estatura, altura sentada; comprimentos da coxa, perna e pé, amplitude de movimento das articulações do quadril, joelho e tornozelo, e força máxima dos músculos do quadríceps). As melhores correlações obtidas usando a combinação das variáveis estudadas foram: $\mathrm{r}=0,35$ para a transição andar-correr e 0,31 para a transição correr-andar. A variável que apresentou a melhor correlação individual foi o comprimento da coxa e a melhor combinação entre as variáveis antropométricas foi obtida na divisão entre o comprimento da coxa e a altura sentada. Esses dados parecem estar em consonância com os de outros estudos aqui apresentados, revelando baixa associação entre o tamanho dos segmentos e a velocidade de transição caminhada-corrida.

É interessante observar que as correlações encontradas nos estudos revisados são opostas às observadas em pesquisas envolvendo quadrúpedes. Por exemplo, no estudo de Heglund e Taylor ${ }^{15}$, o comprimento da perna e a massa corporal foram excelentes preditores para as mudanças no modo de andar. Deve ser notado que a probabilidade de achar altas correlações antropométricas com o modo de andar humano é menor, pois os estudos entre as espécies de quadrúpedes consideram a massa, o comprimento dos membros, a altura e outras características físicas, enquanto os estudos da variação humana, necessariamente, lidam com grupos menores de dados dentro das espécies. Em adição, é possível que esses estudos possam não ter examinado todas as potenciais características antropométricas críticas que poderiam influenciar na velocidade de transição entre o andar e o correr. Em relação a isso, chama a atenção o fato de que as características inerciais do membro inferior não foram consideradas em nenhum desses

\footnotetext{
1 Número Froude é expresso pela seguinte equação: v2/Lg, em que: $\mathrm{v}=$ velocidade de transporte, $\mathrm{L}=$ comprimento do membro inferior e $\mathrm{g}=$ aceleração da gravidade.
} 
estudos $^{6}$. Por isso, na tentativa de melhor caracterizar a influência das medidas antropométricas na transição entre os modos de locomoção, estes últimos autores conduziram um experimento no qual foi utilizada uma amostra com grande variabilidade de características antropométricas. Além disso, incluíram-se na análise dos dados algumas características inerciais e medidas de força dos membros inferiores. Para tanto, avaliaram-se 42 indivíduos, para os quais a velocidade de transição andar-correr e correr-andar foi determinada previamente. Foram obtidas as seguintes medidas antropométricas: massa corporal, estatura, altura sentada, comprimento da perna (maléolo lateral ao eixo do joelho), comprimento da coxa e comprimento total da perna (trocanter maior até o maléolo lateral). Além disso, foram medidas a força de extensão e a de flexão do joelho, usando um dinamômetro isocinético. Os dados antropométricos foram usados para calcular o índice de massa corpórea, a divisão entre o comprimento total da perna e o comprimento da perna, e o momento de inércia da perna em posição totalmente estendida. Os coeficientes de correlação de Pearson foram computados para determinar se a velocidade de transferência preferida relacionava-se linearmente com qualquer uma das variáveis antropométricas. As variáveis que mostraram ser mais bem correlacionadas com a velocidade média de transição preferida foram então submetidas à regressão múltipla, na tentativa de produzir uma equação preditora.

Poucas das variáveis antropométricas puderam exibir coeficientes de correlação com a velocidade de transição preferida, mesmo nas que tinham melhores correlações; a diferença na velocidade de transição preferida, explicada pelas variáveis antropométricas, era pequena. Quando a correlação significativa entre velocidade de transição média e estatura foi deduzida para amostras combinadas, a estatura contribuiu apenas para $20 \%$ da variação entre indivíduos na velocidade de transição. Análises de regressão múltipla, combinando as variáveis que melhor se correlacionaram dentro da amostra, foram incapazes de produzir uma equação capaz de predizer a velocidade de transição preferida que fosse melhor do que as obtidas a partir de variáveis antropométricas isoladas. Em conclusão, os autores salientaram que os estudos em seres humanos parecem compatíveis com a visão de que as diferenças individuais nas dimensões corporais são pequenas, ou que, no máximo, pode haver correlação moderada entre diferenças individuais e a velocidade de transição preferida. Além disso, os resultados contraditórios nos estudos examinando a relação entre a antropometria e a velocidade de transição preferida nos humanos e em outras espécies quadrúpedes têm várias possíveis explicações. Em primeiro lugar, os estudos que demonstraram forte relação trabalharam com grande quantidade de espécies, passando por cima da diversidade considerável da forma e do tamanho dos corpos, envolvendo espécies que variavam em massa corporal total. Dada a pequena variabilidade da massa corporal nas amostras humanas, ao menos naquelas utilizadas nas pesquisas publicadas, não é surpresa que os coeficientes de correlação dos estudos nos humanos sejam muito menores do que os encontrados em uma variedade de animais. A segunda explicação para a discrepância entre as forças das relações entre antropometria e a velocidade de transição preferida, encontrada em estudos com humanos e com quadrúpedes, envolve o modo de locomoção. Comparações entre a transição caminhada-corrida nos homens e o trotegalope nos quadrúpedes podem ser inapropriadas, se os mecanismos fundamentais desse fenômeno são diferentes.

Outro aspecto a ser destacado reside na influência da intencionalidade na modificação da forma de locomoção, que levaria a uma transição entre os atos de andar e correr. Fazendo menção a este aspecto, Bonnard e Paaihous ${ }^{58}$ demonstraram a capacidade da intencionalidade em alterar a relação entre freqüência e amplitude da passada de caminhada, em intensidade realizada em steady-state. Getchell e Whitall ${ }^{57}$ estenderam essa proposição para o controle do modo de locomoção como um meio de explicar as fracas relações que eles observaram entre as variáveis antropométricas e as várias transições no modo de locomoção no adulto humano. Para Hanna et al. ${ }^{6}$, se a intencionalidade impõe uma dinâmica adicional na dinâmica natural no modo de locomover-se, e se essa intencionalidade envolve primariamente a atividade cognitiva, então é plausível que o mais alto desenvolvimento cognitivo dos humanos possa contribuir para o papel diminuído dos parâmetros físicos na determinação no modo de locomover-se preferido nos humanos em comparação com os quadrúpedes, especialmente aqueles com desenvolvimento cortical muito limitado. Todavia, a literatura ainda é carente de pesquisas que venham consubstanciar o papel do efeito cortical na dinâmica do movimento humano, principalmente em velocidades que caracterizam uma transição entre a caminhada e a corrida.

Sumarizando esta seção, pode-se dizer que as variáveis antropométricas parecem ser secundárias em relação a outros fatores na determinação da transição entre o andar e o correr nos humanos. Contudo, não se pode excluir sua atuação no processo, sendo necessária a realização de estudos futuros para melhor determinar a magnitude de sua atuação. Nesse sentido, um interessante aspecto a ser explorado diz respeito à possibilidade de as dimensões corporais influenciarem de forma diferenciada na seleção do modo de locomoção em indivíduos de diferentes faixas etárias, como crianças, adultos jovens e idosos. $\mathrm{O}$ mesmo pode ser 
dito em relação ao sexo, devido às diferenças existentes na composição corporal.

\section{DEMANDA ENERGÉTICA E TRANSIÇÃO CAMINHADA-CORRIDA}

Uma das hipóteses mais estudadas, e talvez a mais aceita, como o principal mecanismo envolvido na transição caminhada-corrida, é a minimização do dispêndio energético $0^{4,6,9-16,19}$. De fato, a velocidade de transição experimentalmente observada foi bem próxima da energeticamente ótima, sugerindo que os executantes adotavam espontaneamente o padrão de locomoção levado pela menor demanda. Em outras palavras, pode-se dizer que, a partir da velocidade na qual andar implica maior gasto de energia, os indivíduos optam por selecionar a corrida como forma de locomoção. Contudo, as evidências ainda são inconclusivas para assumir esse mecanismo como o principal gatilho responsável pelo fenômeno de transição entre a caminhada e a corrida.

No que diz respeito aos experimentos em animais, Farley e Taylor ${ }^{59}$ sugeriram que a redução do gasto energético pode não ser o estímulo para a transição do modo de locomover-se. Medindo a demanda energética e as velocidades associadas com a transição trote-galope em cavalos, esses autores demonstraram que os animais mudavam o modo de locomover-se a velocidades mais baixas que aquelas consideradas ótimas. Foi sugerido que o gatilho para a transição trote-galope ocorria devido a um fator de natureza mecânica, gerado pela necessidade de reduzir o estresse imposto pela tensão óssea e pelos picos de força muscular. Essa argumentação foi provada através de evidências experimentais, mostrando que os cavalos transportando cargas faziam a transição para o galope a uma velocidade mais baixa do que as consideradas ótimas. De fato, na grande maioria dos vertebrados, os padrões do modo de andar nunca são adotados de forma a causar estresse nas articulações e ossos que seja maior que dois terços do necessário para quebrá-los ${ }^{60}$.

Contrapondo-se ao estudo anterior, Hoyt e Taylor ${ }^{11}$ apoiaram a noção de que o custo energético desempenha um papel crítico na expressão dos padrões de locomoção. Pesquisando pôneis, os autores mostraram que a auto-seleção da forma de locomoção para o andar, trotar e galopar resultou em menor gasto energético. Isso sugere que os animais são sensíveis ao gasto energético da atividade, sendo capazes de selecionar a velocidade que minimiza o custo metabólico do transporte dentro de um modo particular de locomoção. Nas velocidades não ótimas para os mesmos padrões de movimento, foi observado que o custo energético foi substancialmente mais alto nos pôneis. Como vis- to, nos estudos envolvendo animais, as evidências ainda são inconclusivas para apoiar a noção de que a demanda energética traduz o principal gatilho a desencadear a transição entre os modos de locomoção.

Mais recentemente, para avaliar o papel da demanda energética na seleção do modo de locomoção em humanos, Hanna et al. ${ }^{6}$ estudaram 15 indivíduos cuja velocidade de transição preferida era conhecida. Comparou-se a velocidade média de transição preferida obtida pelos participantes com o valor previsto, obtido pela interseção das curvas metabólicas derivadas de cada um dos testes de andar-correr. Todos os participantes correram com velocidade acima e abaixo dos seus pontos de transição preferidos e, a partir daí, foram obtidas curvas para o $\dot{\mathrm{V}}_{2}\left(\mathrm{ml} . \mathrm{kg} .{ }^{-1} \mathrm{~min}\right.$ $\left.{ }^{1}\right)$ e para o gasto energético relativo $\left(\mathrm{ml} \cdot \mathrm{kg} .{ }^{-1} \mathrm{~min}^{-1} \cdot \mathrm{m}^{-1}\right)$ versus a velocidade (\% da velocidade de transição preferida). $\mathrm{O}$ mesmo procedimento foi seguido para o ato de andar. Posteriormente, determinou-se e comparou-se a velocidade de deslocamento na interseção dos testes de andar e correr com os valores médios da velocidade de transição preferida, obtidos anteriormente. Para os autores, a premissa da comparação baseava-se em duas possíveis formas de análise. Caso esses pontos coincidissem, a transição ocorreria como um mecanismo para minimizar o gasto energético. Em contrapartida, a discrepância dos pontos poderia levar à discussão de outros fatores que não a redução da demanda energética a influenciar no modo de locomover-se.

A velocidade ótima de transição, em termos energéticos, foi de $99,6 \%$ da velocidade de transição preferida. Esses resultados evidenciaram que a minimização do gasto energético tem um papel significativo na determinação da velocidade na qual a mudança dos modos de locomover-se ocorre. Como apresentado nos dados de consumo de $\mathrm{O}_{2}$, a velocidade de transição ótima em termos energéticos coincidiu com a velocidade média de transição preferida. Nesse caso, a velocidade de transição ótima em termos energéticos era de $100,5 \%$ da velocidade de transição preferida. Enquanto a ação de andar era considerada mais desgastante que correr, acima do ponto de transição, não foi verificada diferença expressiva na percepção do esforço entre os modos de locomover-se, antes ou no ponto de transição. Concluiu-se, então, que a otimização da eficiência energética é o ponto central para a transição entre os modos de locomoção. A questão que permanece obscura, no entanto, é se os humanos podem perceber esse aumento no gasto energético sempre, ou suficientemente rápido para disparar a transição, ou, simplesmente colocado no contexto fisiológico, qual é o receptor que percebe esse estímulo. Obviamente, para responder a essa questão, esforços adicionais são necessários. 
Em congruência ao estudo mencionado anteriormente, para verificar a hipótese de que, durante o aumento de velocidade, a transição entre a caminhada e a corrida corresponde à velocidade na qual andar torna-se menos econômico do que correr, Mercier et al. ${ }^{19}$ determinaram a velocidade da transição e mediram o gasto energético durante o steady-state na velocidade de transição entre os modos de locomoção. Em adição, também foi investigado o efeito do tipo de locomoção nas respostas cardiorrespiratórias acima e abaixo do ponto de transição. Para tanto, os indivíduos caminharam e correram nas velocidades correspondentes a $\pm 0,5 \mathrm{~km} \cdot \mathrm{h}^{-1} \mathrm{e} \pm 1 \mathrm{~km} \cdot \mathrm{h}^{-1}$ da velocidade de transição. A amostra foi composta por sete adultos jovens. Cada sujeito submeteu-se a quatro testes, a saber: a) teste máximo para determinar o consumo máximo de oxigênio e o limiar ventilatório; b) teste para determinar a velocidade de transição espontânea; c) teste para andar na velocidade de transição, na velocidade de transição $\pm 0,5 \mathrm{~km} \cdot \mathrm{h}^{-1}$ e na velocidade de transição $\pm 1 \mathrm{~km} \cdot \mathrm{h}^{-1}$; d) teste para correr na velocidade de transição, na velocidade de transição \pm $0,5 \mathrm{~km} \cdot \mathrm{h}^{-1}$ e na velocidade de transição $\pm 1 \mathrm{~km} \cdot \mathrm{h}^{-1}$.

Vários achados importantes foram verificados nesse estudo. Como principal resultado, destacou-se que a transição entre a caminhada e a corrida correspondia à velocidade na qual correr ficou mais econômico. Então, acima deste nível verificou-se que a corrida acarretou redução das respostas cardiorrespiratórias comparadas para o andar a uma mesma velocidade. O correr ficou mais econômico do que o andar, em velocidade de transição igual a $2,16 \mathrm{~m} \cdot \mathrm{s}^{-1}$ (erro padrão da média de 0,04 ), o que está de acordo com a variação dos valores da velocidade de transição $(1,30$ $2,55 \mathrm{~m} . \mathrm{s}^{-1}$ ) reportados por Thorstensson e Roberthson ${ }^{56}$. Está também compatível com a velocidade $\left(2 \mathrm{~m} . \mathrm{s}^{-1}\right)$ a partir da qual outros investigadores evidenciaram que correr era mais econômico ${ }^{10,61}$. No entanto, é difícil determinar, a partir desses resultados, se um aumento no custo da locomoção induziu mudança no padrão locomotor ou se a redução do custo da locomoção foi conseqüência da mudança no padrão de movimento. Outro aspecto relevante desse estudo é que, apesar de notáveis diferenças terem sido observadas para o $\dot{\mathrm{VO}}_{2}$, a FC e a VE, durante a caminhada e a corrida abaixo e acima da velocidade de transição, os autores não observaram diferenças em $\mathrm{R} \mathrm{e} \mathrm{VE} / \mathrm{VO}_{2}$, sugerindo que, para a variação de velocidade estudada, o tipo de locomoção não afeta o substrato utilizado e a ligação entre VE e o gasto energético. Em conclusão, verificou-se que a transição entre a caminhada e a corrida corresponde à velocidade na qual correr se torna mais econômico que andar. Acima dessa velocidade de transição, correr resultou em redução relativa do custo da locomoção e das respostas cardiorrespiratórias. Não obstante todos esses achados, é importante res- saltar que autores como Mercier et al. ${ }^{19}$ chamam a atenção para o fato de que os mecanismos dessa relação não estão ainda completamente claros, necessitando de outras investigações para melhor elucidação.

Os dados até aqui apresentados sugerem que o principal mecanismo que rege a transição entre a caminhada e a corrida é a minimização da demanda energética. Isso parece estar de acordo com outras observações experimentais ${ }^{18}$, nas quais se concluiu que a transição entre os modos de locomover-se era dirigida pela redução do custo fisiológico. A evidência desses estudos mostrou que, para cada participante, havia alta coincidência na velocidade de transição e o ponto em que a $\mathrm{FC}$ e o $\dot{\mathrm{V}}_{2}$ para andar e correr ficavam equivalentes. Todavia, assumir esse pressuposto como o principal responsável pela mudança na forma de locomoção, isto é, uma relação causal, não tem sido unanimidade aceita entre os pesquisadores.

Brisswalter e Mottet ${ }^{21}$ estudaram as relações entre o custo energético da locomoção e a variabilidade da duração do passo da velocidade de transição, de acordo com o modo de locomoção imposto ou escolhido pelos indivíduos. Um sensor de pressão foi utilizado nos pés de 10 indivíduos para determinar a ocorrência do contato com o solo para cada pé. O gasto energético, por unidade de distância, foi calculado de acordo com a equação proposta por Di Prampero $^{62}$ e o procedimento reuniu as seguintes etapas: adaptação à esteira, determinação da velocidade de transição preferida, gravação da variabilidade imposta aos padrões de locomoção (correr e andar). A variabilidade da duração da passada foi descrita usando o coeficiente de variação para cada pessoa ${ }^{63}$. Para calcular a velocidade de transição ótima em termos energéticos, uma regressão foi feita usando os valores do gasto energético para cada pessoa. Uma função quadrática curvilínea foi escolhida para ajustar os dados da caminhada e uma função linear foi usada para os dados da corrida. A interseção entre as melhores curvas de ajuste individual foi considerada a velocidade de transição ótima. Como principal resultado do estudo, os autores destacaram que a velocidade de transição ótima em termos energéticos foi mais alta que a velocidade de transição selecionada pelos praticantes $\left(7,89 \pm 0,34 \mathrm{~km} \cdot \mathrm{h}^{-1}\right.$ versus 7,66 $\left.\pm 0,57 \mathrm{~km} \cdot \mathrm{h}^{-1}, \mathrm{p}<0,05\right)$. Na condição de transição escolhida pela pessoa, foi encontrado um efeito significativo da velocidade na variabilidade da duração da passada. Esse resultado foi compatível com o estudo de Hreljac ${ }^{39}$, indicando que a transição entre o andar e o correr não é exclusivamente um mecanismo fisiológico de economizar energia. Reportando-se aos dados da literatura, Brisswalter e Mottet ${ }^{21}$ realçaram o papel das razões locais metabólicas, mecânicas e cinemáticas para a troca no padrão de locomoção. Nesse sentido, parece existir certo consenso entre 
alguns pesquisadores, apontando na direção de que ainda é difícil identificar os mecanismos completos da transição ${ }^{19}$, 20,22,41.

Hreljack $^{39}$ apresentou evidências de que a transição andar-correr em humanos também ocorreria a velocidades mais baixas do que as energeticamente ótimas, concluindo que a minimização do gasto energético não era o mecanismo que dirigia essa transição. Em estudo posterior, Hreljack $^{40}$, buscando o gatilho mecânico da transição, no qual algumas variáveis cinéticas foram medidas (percentual de carga máxima, frenagem, impulso propulsivo e força de pico), concluiu que os fatores cinéticos também não eram o gatilho para a transição andar-correr nos humanos.

Após análise das pesquisas disponíveis, é sensato assumir que múltiplos objetivos podem ser otimizados durante a locomoção. Nesse caso, a proposição da minimização da demanda metabólica de energia como único critério de otimização do passo humano pode ser uma simplificação demasiada do fenômeno. Patla e Sparrow ${ }^{22}$, criticando o emprego do custo energético como indicador crítico na expressão dos padrões de locomoção, destacam alguns pontos importantes. Entre eles, podemos citar: a) as curvas de consumo de oxigênio versus a velocidade de locomoção, obtidas em estudos realizados com animais, não mostram uma velocidade mínima única e singular, apontando a existência de mais de uma velocidade de locomoção em que o consumo de oxigênio é similar; b) a medida do consumo de oxigênio implica que o combustível anaeróbio não é um fator principal durante a locomoção; isso não obrigatoriamente ocorre para a corrida; c) durante a locomoção ocorre um débito energético que é reposto pelo sistema cardiorrespiratório após o fim da atividade; quando andamos devagar, não estamos próximos dos limites do sistema cardiorrespiratório em fornecer combustível de forma aeróbia; porém, quando consideramos andar ou correr em altas velocidades, esse débito energético não pode ser descontado; além disso, o custo energético anaeróbio que não é utilizado na medida do consumo de oxigênio também deve ser levado em consideração, pois representa uma demanda de energia; d) a eficiência dos movimentos está associada ao uso do consumo de oxigênio e a minimização dessa variável implica que o movimento é mais eficiente; entretanto, esse indicador representa o denominador da equação de eficiência; o trabalho mecânico é o numerador dessa equação. Esse último indicador não inclui apenas o trabalho externo de mover o centro de massa de um corpo de um ponto para o outro, mas também o trabalho mecânico interno de mover os membros ciclicamente. Desde que os estudos do custo energético geralmente envolvem pessoas andando ou correndo na esteira, não estamos lidando com trabalho mecânico externo (centro de massa não é teorica- mente deslocado); apenas o trabalho mecânico interno tem que ser considerado no numerador. O problema é que calcular o trabalho mecânico interno não é fácil. Além disso, não existe um consenso sobre qual a melhor forma de realizar essa medida.

\section{ESTABILIDADE LOCOMOTORA E TRANSIÇÃO CAMINHADA-CORRIDA}

A uma dada velocidade de locomoção, as pessoas selecionam o comprimento da passada que leva a uma redução da demanda energética ${ }^{12,64}$. Se essa velocidade aumenta, chegará um momento em que o padrão de movimento terá que ser alterado. Logo, o custo metabólico como uma função da velocidade para o andar e o correr mostra que as economias de energia podem ser atingidas através da troca do correr para o andar e vice-versa ${ }^{65}$. Contudo, alguns autores $^{36,39}$ têm atribuído a mudança da forma de locomoverse à estabilidade dos padrões de locomoção. Vejamos o que as evidências apresentam nesse sentido.

A locomoção quadrúpede pode ser considerada estável devido à ampla base de apoio oferecida por três membros de cada vez ${ }^{66}$. Já a locomoção bípede apresenta uma característica instável para a maioria dos ciclos de passos. Tal fato ocorre porque o centro de massa do corpo está fora da base de apoio (definida pelos pés) em $80 \%$ do tempo. Por isso, as considerações da estabilidade são mais desafiadoras no ser humano, um bípede, do que em quadrúpedes. Ao lidar com as questões associadas à estabilidade na locomoção, temos que considerar tanto o deslocamento quanto a velocidade do centro de massa do corpo. Não é surpresa que recursos consideráveis do sistema sensório-motor sejam utilizados para manutenção da estabilidade dinâmi$\mathrm{ca}^{22}$.

Se as mudanças no padrão de locomoção são dominadas pelos mecanismos de economia de energia, poderia esperar-se que as transições ocorressem sempre nesses pontos, em que o gasto energético é mínimo. Na literatura, existe crescente evidência contra essa proposta. Como visto anteriormente, Farley e Taylor ${ }^{59}$ mostraram que cavalos trocam do trotar para o galopar a uma velocidade na qual o galopar é menos eficiente que o trotar em termos metabólicos. Nesse estudo, os autores verificaram que, em cavalos treinados para manter o padrão de locomoção a uma velocidade não usual, a transição espontânea entre o trotar e o galopar ocorria a uma velocidade mais baixa em relação ao mesmo custo metabólico $(-26 \%)$, implicando uma estratégia aparentemente não econômica. A partir da constatação de que os cavalos com sobrecargas efetuavam a troca do modo de locomoção a velocidades mais baixas, levantou-se a hipótese de que a velocidade de transição 
seria escolhida visando uma manutenção das estruturas músculo-esqueléticas. Tanto os cavalos com sobrecarga quanto aqueles que não portavam cargas adicionais trocaram o padrão de locomoção a diferentes velocidades, porém, a um mesmo pico vertical de estresse agindo sobre os músculos, tendões e ossos, enfatizando o critério de minimização da força em oposição ao critério da economia energética. Em conclusão, os autores assumiram que o modo de locomoção é abandonado em favor de outro, quando o último resulta em menor estresse músculo-esquelético a uma mesma velocidade. Apesar das dificuldades de aplicar os dados de Farley e Taylor ${ }^{59}$ aos humanos (devido às diferenças na mecânica da locomoção entre homens e animais), os argumentos da viabilização dessa hipótese recaem na possibilidade de ela contribuir para uma possível distinção dos determinantes da locomoção em steady-state, a partir do gatilho que leva à transição.

Poucos estudos têm investigado a influência combinada de indicadores energéticos e de estabilidade na transição caminhada-corrida. Um deles foi realizado por Minetti et $a l .{ }^{64}$, no qual se mediram simultaneamente o gasto metabólico e a frequiência do trabalho mecânico do andar a diferentes velocidades, tanto para a frequiência de passos escolhida, quanto para as freqüências impostas para os indivíduos. Seis homens saudáveis andaram em uma esteira nas velocidades de $0,69,1,39,1,67$ e $2,08 \mathrm{~m} \cdot \mathrm{s}^{-1}$. A cada velocidade, a frequiência de passos escolhida foi computada. Posteriormente, as pessoas foram induzidas a variar a freqüência de passadas, seqüencialmente, ao nível de $\pm 10 \%$ $\mathrm{e} \pm 20 \%$ da freqüência de passadas escolhida. Foram realizadas medidas das seguintes variáveis: a) fisiológica (consumo de oxigênio); b) biomecânicas: características inerciais dos segmentos do corpo (massa, centro de massa e raio de giro; trabalho interno positivo (ou seja, a potência necessária para mover os membros ao centro de massa do corpo); trabalho externo positivo (isto é, a potência necessária para mover o centro de massa do corpo em relação ao ambiente). A soma do trabalho interno mais o externo foi definida como trabalho total, considerado como a potência necessária para sustentar a locomoção. Em conclusão, observou-se que o desvio do gasto metabólico em relação à frequiência de passadas escolhida, para uma velocidade de caminhada constante, pode ser parcialmente explicado pelo aumento da taxa de trabalho mecânico. Em todas as velocidades estudadas, o trabalho necessário para mover o centro de massa do corpo foi o maior determinante. É importante ressaltar que, para altas velocidades, o trabalho necessário para mover os membros desempenha um papel importante na obtenção de uma freqüência mínima de passadas, próximas da frequiência espontânea. No entanto, a pequena confiabilidade da predição da freqüência ótima a velocidades acima de $1,39 \mathrm{~m} \cdot \mathrm{s}^{-1}$ sugere que a metodologia utilizada para computação do trabalho mecânico não reflete totalmente o trabalho real. Logo, apesar de a metodologia utilizada ser a única capaz de fornecer uma explicação racional da freqüência ótima de passadas para o andar ${ }^{67}$, outras estratégias deveriam ser desenvolvidas para obter um conhecimento mais profundo sobre esse assunto.

Numa linha semelhante ao estudo anterior, Minetti et al. ${ }^{20}$ investigaram a influência dos limites fisiológicos e biomecânicos na seleção da velocidade de transição espontânea entre o andar e o correr. Cinco jovens adultos caminharam e correram numa esteira a diferentes inclinações; determinaram-se individualmente para cada inclinação na esteira as regressões do custo metabólico versus a velocidade do andar (polinômio do segundo grau) e correr (função linear). Pela resolução das equações, a maior velocidade na qual o gasto energético em andar era o mesmo que correr foi determinada. $\mathrm{O}$ mesmo procedimento foi aplicado aos dados metabólicos expressos por passada (dividindo-se a taxa do trabalho metabólico pela freqüência de passadas). A velocidade de transição espontânea foi avaliada através da observação nas mudanças no modo de locomoção das pessoas, enquanto a velocidade da esteira variava para menos e para mais, com estágios de $0,1 \mathrm{~km} \cdot \mathrm{h}^{-1}$. Apesar de reconhecerem a forte influência da minimização da demanda metabólica na escolha da velocidade de transição, os autores sugerem que considerar a minimização do esforço metabólico como o principal gatilho que desencadeia a transição caminhada-corrida pode ser um erro, usando a seguinte argumentação: considere andar a uma velocidade próxima da velocidade de transição espontânea e assuma que um pequeno grupo de músculos (gastrocnêmios e solear) está começando a trabalhar ineficientemente. Visando enfrentar uma situação desconfortável, sentida pelos mecanorreceptores periféricos (e correspondente a elevado custo de $\mathrm{O}_{2}$ ), a pessoa decide trocar para o correr, melhorando a eficiência dos gastrocnêmios, mas aumentando o esforço metabólico como resultado da contribuição de mais músculos para permitir a locomoção. Nesse caso, o indivíduo pode optar por conforto na locomoção ao invés de economia metabólica. Além disso, a procura por conforto (mediado por outros aferentes periféricos, tais como os proprioceptores nos músculos, tendões e articulações) pode sugerir a escolha de um modo de locomoção ótimo.

Outro estudo similar, considerando a estabilidade locomotora conjuntamente com os limites energéticos, foi desenvolvido por Holt et al. ${ }^{68}$. Inicialmente, foi solicitado que os voluntários andassem em uma esteira, às suas velocidades preferidas. Posteriormente, os indivíduos andaram em suas freqüências de passadas preferidas, acima e abaixo 
delas. Os dados mostraram que andar nas frequiências preferidas resultou em gastos metabólicos mínimos. Além disso, os autores também mediram a estabilidade da cabeça e das articulações do membro inferior, revelando uma relação complementar entre a estabilidade da cabeça e o custo metabólico. Apesar de as medidas metabólicas e de estabilidade estarem altamente relacionadas, a máxima estabilidade da cabeça foi obtida antes de atingir-se o mínimo gasto energético. De fato, no andar humano os padrões de coordenação envolvendo o tronco (bem como a ligação dos braços e pernas) indicam que existem padrões de coordenação mais ou menos estáveis acima e abaixo de velocidades entre 0,7 e $0,9 \mathrm{~m} \cdot \mathrm{s}^{-1}$, implicando a existência de múltiplos padrões de coordenação no andar. Além disso, no estudo supracitado, diferentes tendências foram observadas no custo energético por quilo por quilômetro percorrido, atingindo o mínimo por volta de $1,0-1,2 \mathrm{~m} \cdot \mathrm{s}^{-1}$. Em outro estudo, a coordenação do tronco mostrou variabilidade máxima antes da velocidade de gasto metabólico mínimo ${ }^{69}$, mostrando que o custo metabólico e as medidas de estabilidade podem mudar significativamente durante o andar. Esses achados apontam para a necessidade de estudar a extensão da relação entre os diversos padrões de movimentos, em diferentes velocidades, para determinar a sua influência na escolha da forma de locomoção. Por isso, esses diferentes padrões precisam ser investigados em mais detalhes, dando maior ênfase às manipulações específicas da estabilidade do sistema ${ }^{70}$.

Apesar da reconhecida importância da estabilidade motora na locomoção humana, ainda não está bem estabelecida a magnitude de sua influência na transição caminhadacorrida. Muitos fatores poderiam ser levantados como responsáveis pela mudança na forma de locomoção, principalmente quando a estabilidade é desafiada a maior grau, como na caminhada ou corrida em terrenos irregulares ou mediante a imposição de algum tipo de sobrecarga no corpo. Para responder a essas questões, ou mesmo àquelas mais básicas em que não existe um desafio acentuado às características normais de estabilidade, estudos futuros devem ser conduzidos. Nesse contexto, seria interessante que as pesquisas considerassem maior tempo de medida do gasto energético, pois os intervalos de tempo adotados até então, provavelmente, são pequenos para realizar inferências mais conclusivas sobre a interação dos aspectos fisiológicos e biomecânicos na estabilidade locomotora. Isso justifica-se na medida em que a influência da instabilidade na realização de tarefas mais demoradas pode ser diferente da verificada nas atividades mais curtas. Além de medidas mais duradouras da demanda energética, outros indicadores que proporcionem o estudo dos limites envolvidos na transição caminhada-corrida devem ser experimentados. Talvez as respostas eletromiográficas ao esforço possam constituir-se em uma ferramenta interessante a ser explorada, o que, aliás, é um aspecto ainda não privilegiado nos estudos acerca dos mecanismos envolvidos na transição caminhada-corrida.

\section{CONSIDERAÇÕES FINAIS E SUGESTÕES PARA ESTUDOS FUTUROS}

A maior parte das pesquisas que investigaram os mecanismos envolvidos na transição caminhada-corrida centrou seus esforços em uma ou duas características principais que pudessem explicar o fenômeno. Assim, os estudos focalizaram suas expectativas nas questões relacionadas à demanda energética, às características antropométricas, ou mesmo aos padrões biomecânicos que, em última instância, estão associados à estabilidade locomotora. Todavia, é difícil assumir que as mudanças no modo de locomoção ocorrem como resposta a uma única característica. Da mesma forma, é ainda mais difícil determinar o percentual de atuação de cada variável no processo.

Apesar do relativo interesse em estudar os mecanismos envolvidos na transição caminhada-corrida, poucos trabalhos têm sido direcionados em investigar quais os efeitos da opção entre as distintas formas de locomoção no condicionamento físico. Para os malcondicionados, a caminhada pode constituir-se em uma atividade adequada para aprimorar a capacidade cardiorrespiratória ${ }^{71,72}$. Por outro lado, para aqueles mais bem condicionados, a corrida parece ser mais apropriada em preencher tal requisito, devido à facilidade para elevar a intensidade do esforço a patamares mais altos que a caminhada. Entretanto, quando é necessário exercitar-se a uma intensidade de esforço entre 6 e 8METs (geralmente apontada como área de transição entre a caminhada e a corrida, compreendendo também a intensidade do trabalho na qual as pessoas não sabem se correm ou caminham), a seleção da forma de locomoção pode ter distintas repercussões.

Com o propósito de investigar a influência da forma de locomoção em algumas variáveis cardiorrespiratórias, Monteiro et al..$^{73}$ conduziram um estudo no qual os indivíduos foram solicitados a caminhar e correr nas mesmas velocidades. Seis indivíduos, propositalmente homogêneos quanto à idade, estatura, comprimento de membros inferiores e peso corporal, submeteram-se a dois esforços de seis minutos (caminhada e corrida). Os testes foram separados por um intervalo de 20 minutos, em quatro dias distintos, com a ordem das atividades definidas por um quadrado latino. A velocidade era de $6,5 \mathrm{~km} \cdot \mathrm{h}^{-1}$ na primeira visita de adaptação ao protocolo e, nos dias subseqüentes, $6,6,5$ e $7 \mathrm{~km} \cdot \mathrm{h}^{-1}$. Identificou-se que a influência do meio da 
locomoção foi mais relevante do que as variações de velocidade. A demanda metabólica expressa pela $\mathrm{FC}, \dot{\mathrm{VO}}_{2}, \mathrm{VCO}_{2}$, VE e pulso de $\mathrm{O}_{2}$ foi maior na corrida do que na caminhada (10 a 50\%) para todas as velocidades testadas $(\mathrm{p}<0,05)$, enquanto os equivalentes ventilatórios de $\mathrm{O}_{2}$ e de $\mathrm{CO}_{2}$ e a percepção subjetiva de esforço geral e localizada (escala de Borg) não diferiram ( $p>0,05)$. Em conclusão, os autores destacaram que, nesses dados preliminares com adultos do sexo masculino de dimensões corporais homogêneas, para as mesmas velocidades na caminhada e na corrida, há respostas cardiorrespiratórias distintas, não se refletindo na percepção local ou global do esforço. Os autores destacaram que a dissociação entre o fenômeno fisiológico e a percepção do esforço pode ser explicada pelo fato de a intensidade do exercício ter sido abaixo do limiar ventilatório, como pode ser observado pelo comportamento dos equivalentes ventilatórios e corroborado pelos valores relativamente baixos da escala Borg.

Apesar de chamarem atenção sobre a importância desses achados para melhor caracterização metabólica da caminhada e da corrida objetivando a seleção da atividade na prescrição do exercício, os dados de Monteiro et al. ${ }^{73}$ são preliminares, impossibilitando inferências mais consistentes sobre o assunto. Para realização de pesquisas futuras que possam melhorar a validade externa do estudo, aspectos metodológicos adicionais devem ser considerados. Entre eles, podem-se citar o número de sujeitos envolvidos na amostra, a adoção de um critério de emparelhamento para aptidão cardiorrespiratória dos avaliados, a aplicação de um protocolo para estabelecer o ponto individual de transição caminhada-corrida, bem como a adoção de outras variáveis, além das cardiorrespiratórias, que possam servir como indicadores de intensidade de esforço. Nesse sentido, as respostas eletromiográficas e de lactacidemia poderiam trazer contribuições potenciais.

Outra possibilidade de estudo consiste em verificar a influência de diferentes combinações de atividade motora, desempenhadas na velocidade de transição caminhada-corrida, nas respostas cardiorrespiratórias, eletromiográficas e de percepção subjetiva de esforço. Após delimitação de um tempo de esforço fixo para coleta de dados, poderiam ser analisados os efeitos das seguintes combinações de locomoção: a) somente caminhada; b) somente corrida; c) caminhada e corrida, em que cada atividade seria realizada de forma contínua durante a metade do tempo; d) caminhada e corrida, na qual cada atividade seria realizada de forma intervalada durante a metade do tempo. Embora seja consenso que, do ponto de vista físico, a demanda energética independe do modo de locomoção, é possível que a demanda metabólica possa diferir na mesma velocidade entre essas duas modalidades. Elucidar essa questão pode constituir uma importante ferramenta para seleção da forma de treinamento, principalmente para indivíduos que apresentam baixa capacidade funcional.

Outro aspecto não explorado na literatura, e que poderia oferecer contribuições relevantes para a seleção da forma de locomoção em programas de condicionamento físico, diz respeito ao estudo das respostas fisiológicas em populações com capacidade funcional muito reduzida. Analisando os dados disponíveis, observa-se que as pesquisas direcionadas ao fenômeno da transição caminhada-corrida não têm enfatizado esse aspecto. Para preencher essa lacuna, uma proposta interessante seria verificar a relação entre as variáveis de trocas gasosas respiratórias e as respostas eletromiográficas na escolha da velocidade de transição em indivíduos com aptidão cardiorrespiratória elevada e em indivíduos com aptidão reduzida, como idosos ou cardiopatas. Nesse caso, poderiam ser identificadas as variáveis mais significativas a influenciar na velocidade de transição entre os grupos, além de analisadas suas diferenças e possíveis implicações para o condicionamento físico.

Finalmente, pode-se apontar uma lacuna de ordem prática. A seleção dos conteúdos de um programa de exercícios passa, inicialmente, pela concepção dos seus objetivos - em se tratando de praticantes malcondicionados, a escolha da forma de locomoção pode exercer influência, não só nas possibilidades de condicionamento, mas também na adesão desses praticantes. Pesquisas conduzidas até o momento tentaram descrever os mecanismos envolvidos na transição caminhada-corrida, sem, contudo, investigar os seus efeitos no condicionamento físico dos indivíduos. Acreditamos que essa lacuna mereça atenção, podendo ajudar a elucidar os conceitos físicos envolvidos no cálculo da demanda energética, mas também os mecanismos e implicações da forma de locomoção para a prescrição de exercícios. Em suma, a revisão das pesquisas disponíveis sobre a transição entre o andar e o correr sugere que, tanto em termos de descrição teórica quanto em termos de aplicação em situações de prescrição do exercício, as dúvidas superam as certezas.

\section{REFERÊNCIAS}

1. Melby CL, Ho RC, Hill JO. Assessment of human energy expenditure. In: Bouchard $\mathrm{C}$, editor. Physical activity and obesity. Champaign: $\mathrm{Hu}-$ man Kinetics 2000:103-31.

2. Araújo CGS. Teste de exercício: terminologia e algumas considerações sobre passado, presente e futuro baseadas em evidências. Rev Bras Med Esporte 2000;6:77-84.

3. Ainsworth BE, Haskel WL, Leon AS, Jacobs DR, Montoye HJ, Sallis JF, et al. Compendium of human activities: classification of energy costs of human physical activities. Med Sci Sports Exerc 1993;25:71-81.

4. Margaria R. Biomechanics and energetics of human exercise. Oxford: Oxford University Press, 1976. 
5. American College of Sports Medicine. Guidelines for exercise testing and prescription. $6^{\text {th }}$ ed. Philadelphia: Williams and Wilkins, 2000.

6. Hanna A, Abernethy B, Burgess-Limerick B. Triggers of the transition between human walking and running. In: Sparrow, WA, editor. Energetics of human activity. Champaign: Human Kinetics, 2000:124-64.

7. Ralston HJ. Energy-speed relation and optimal speed duration level walking. Int Z Angew Physiol Arbeitsphysiol 1958;(Suppl 17):277-83.

8. Knuttgen MG. Oxygen uptake and pulse rate while running with undetermined and determined stride length at different speeds. Acta Physiol Scand 1961;52:366-71.

9. Zarrugh NY, Todd FN, Ralston HJ. Optimization of energy expenditure during level walking. Eur J Appl Physiol 1974;33:293-306.

10. Grillmer S, Halbertsma J, Nilsson J, Thorstensson A. The adaptation to speed in human locomotion. Brain Res 1979;165:177-82.

11. Hoyt DF, Taylor CR. Gait and the energetics of locomotion in horses. Nature 1981;292:239-40.

12. Cavanagh PR, Willians KR. The effect of stride length variation on oxygen uptake during distance running. Med Sci Sports Exerc 1982;14:305.

13. McMahon TA. The role of compliance in mammalian running gaits. $\mathrm{J}$ Exp Biol 1985;115:263-82.

14. Cavagna GA, Franzetti P. The determinants of step frequency in walking in humans. J Physiol (Lond) 1986;373:235-42.

15. Heglund NC, Taylor CR. Speed, stride frequency and energy cost per stride: how do they change with body size and gait? J Exp Biol 1988; 138:301-18.

16. Alexander RM. Optimization and gaits in the locomotion of vertebrates. Physiol Rev 1989; 69:1199-227.

17. Holt KG, Hamill J, Andres RO. Predicting the minimal energy costs of human walking. Med Sci Sports Exerc 1991;23:491-8.

18. Durand M, Goudal G, Mercier J, LeGallais D, Micallef JP. Energy correlate of gait change according to locomotion speed. J Hum Stud 1994; $26: 187-203$

19. Mercier J, LeGallais D, Durand M, Goudal C, Micallef JP, Prefaut C. Energy expenditure and cardiorespiratory responses at the transition between walking and running. Eur J Appl Physiol 1994;69:525-9.

20. Minetti AE, Ardigo LP, Saibene F. The transition between walking and running in humans: metabolic and mechanical aspects at different gradients. Acta Physiol Scand 1994;150:315-24.

21. Brisswalter J, Mottet D. Energy cost and stride duration variability at preferred transition gait speed between walking and running. Can J Appl Physiol 1996;21:471-80.

22. Patla AE, Sparrow WA. Factors that have shaped human locomotor structure and behavior: the jewels in the crown. In: Sparrow WA, editor. Energetics of human activity. Champaign: Human Kinetics, 2000:43-65.

23. Grieve DW. Gait patterns and the speed of walking. Biomed Eng 1968; 3:119-22.

24. Inman VT, Ralston HJ, Tood F. Human walking. Baltimore: Williams and Wilkins, 1981.

25. Wollacott MH, Jensen JL. Posture and locomotion. In: Heuer H, Keele SW, editors. Handbook of perception and action. Motor Skills 1996:333403.

26. Cavagna GA, Saibene FP, Margaria R. External work in walking. J Appl Physiol 1963;18:1-19.

27. Alexander RMcN. Optimum walking techniques for quadrupeds and bipeds. J Zool 1980;192:97-117.

28. Alexander, RMcN. A model of bipedal locomotion on compliant legs. Philos Trans R Soc Lond 1992; 338b: 189-98.
29. Alexander RMcN, Maloiy GMO. Stride lengths and stride frequencies of primates. J Zool 1984;202:577-82.

30. Bickhan R. The spring-mass model for running and hopping. J Biomech 1989;22:1217-27.

31. McGeer T. Passive dynamic walking. Int J Robotics Res 1990;9:62-82.

32. McMahon TA, Cheng GC. The mechanics of running: how does stiffness couple with speed? J Biomech 1990;23:65-78.

33. Mochon S, McMahon TA. Ballistic walking. J Biomech 1980;13:49-57.

34. Minetti AE, Saibene F. Mechanical work rate minimization and freely chosen stride frequency of human walking: a mathematical model. J Exp Biol 1992;170:19-34.

35. Alexander RMcN. Walking and running. American Scientist 1984;72: 348-54.

36. Diedrich FJ, Warren Jr WH. Why change gaits? Dynamics of the walk run transition. J Exp Biol 1995;21:183-202.

37. Holt KG, Hamill J, Andres RO. The force-driven harmonic oscillator as a model for human locomotion. Hum Movement Sci 1990;9:55-68.

38. Beuter A, Lalonde F. Analysis of a phase transition in human locomotion using singularity theory. Neurosci Res Commun 1989;127-32.

39. Hreljac A. Preferred and energetically optimal gait transition speeds in human locomotion. Med Sci Sports Exerc 1993a;25:1158-62.

40. Hreljac A. Determinants of the gait transition speed during human locomotion: kinetic factors. Gait and Posture 1993b;1:217-23.

41. Hreljac A. Determinants of the gait transition speed during human locomotion: kinetic factors. J Biomech 1995a;28:669-77.

42. Hreljac A. Effects of physical characteristics on the gait transition speed during human locomotion. Hum Movement Sci 1995b;14:205-16.

43. Araújo CGS. Manual de teste de esforço. 2a ed. Rio de Janeiro: Ao Livro Técnico, 1984.

44. Abernethy B, Burges-Limerik RJ, Engstron C, Hanna, A. Temporal coordination of human gait. In: Glencross DJ, Piek JP, editors. Motor control and sensory-motor integration: issues and direction. Amsterdam: North-Holland Elsevier, 1995:171-98.

45. Bassett DR, Giese Jr MD, Nagle FJ, Ward A, Raab DM, Balke B. Aerobic requirements of overground versus treadmill running. Med Sci Sports Exerc 1985;17: 477-81.

46. Pink M, Perry J, Houglum PA, Devine DJ. Lower extremity range of motion in the recreational sport runner. Am J Sports Med 1994;22:5419.

47. McMiken DF, Daniels JT. Aerobic requirement and maximum aerobic power in treadmill and track running. Med Sci Sports Exerc 1976;8:147.

48. Schenau GJI. Some fundamental aspects of the biomechanics of overground versus treadmill locomotion. Med Sci Sports Exerc 1980;12:25761.

49. Elliott BC, Blanksby BA. A cinematography analysis of overground and treadmill running by males and females. Med Sci Sports Exerc 1976;8: 84-7.

50. Nelson RC, Dillman CJ, Lagasse P, Bickett P. Biomechanics of overground versus treadmill running. Med Sci Sports Exerc 1972;4:233-40.

51. Pugh LGCE. Oxygen intake in track and treadmill running with observations on the effects of air resistance. J Physiol 1970;207:823-35.

52. Frishberg BA. An analysis of overground and treadmill sprinting. Med Sci Sports Exerc 1983;15:478-85.

53. Pugh LGCE. The influence of wind resistance in running and walking and the mechanical efficiency of work against horizontal or vertical forces. J Physiol 1971;213:255-76.

54. Nigg BN, De Boer RW, Fisher V. A kinematic comparison of overground and treadmill running. Med Sci Sports Exer 1995;27:98-105. 
55. Brisswalter J, Legros P, Durand M. Running economy, preferred step length correlated to body dimensions in elite middle distance runners. J Sports Med Phys Fitness 1996;36:7-15.

56. Thorstensson A, Roberthson H. Adaptations to changing speed in human locomotion: speed of transition between walking and running. Acta Physiol Scand 1987;131:211-4.

57. Getchell N, Whitall J. Transitions in gait as a function of physical parameters [abstract]. J Sport Exerc Psychol 1997;(Suppl 55):19.

58. Bonnard M, Paaihous J. Intentionally in human gait control: modifying the frequency-to-amplitude relationship. J Exp Psychol Hum Percept Perform 1993;19:429-43.

59. Farley CT, Taylor CR. A mechanical trigger for the trot-gallop transition in horses. Science 1991;253:306-8.

60. Rubin CT, Lanyon LE. Dynamic strain similarity in vertebrates: an alternative to allometric limb bone scaling. J Theor Biol 1984;107:321-7.

61. Margaria R, Cerretelli P, Aghemo P, Sassi G. Energy cost of running. J Appl Physiol 1963;18:367-70.

62. Di Prampero PE. The energy cost of locomotion on land in water. Int J Sports Med 1986;7:55-72.

63. Maruyama $\mathrm{H}$, Nagasaki $\mathrm{H}$. Temporal variability in the phase duration during treadmill walking. Hum Movement Sci 1992;11:335-48.

64. Minetti AE, Capelli C, Zamparo P, Di Prampero PE, Saibene F. Effects of stride frequency on mechanical power and energy expenditure of walking. Med Sci Sports Exerc 1995;27:1194-212.
65. Minetti AE, Alexander McN. A theory of metabolic costs for bipedal gaits. J Theor Biol 1997;186:467-76.

66. Ting LH, Blickhan R, Full RJ. Dynamic and static stability in hexapedal runners. J Exp Biol 1994;197:251-69.

67. Cavagna GA, Kaneko M. Mechanical work and efficiency in level walking and running. J Physiol 1977;268:467-81.

68. Holt KG, Jeng SF, Ratcliffe R, Hamill J. Energetic cost and stability during human walking at the preferred stride frequency. J Mot Behav 1995;27:164-78

69. Wagenaar RC, Van Emmerick REA. The dynamics of pathological gait: stability and adaptability of movement coordination. Hum Movement Science 1994;13:441-71.

70. Caldwell GE, Van Emmerick REA, Hamill J. Movement proficiency: task demands and constraints in assessing human movement. In: Sparrow WA, editor. Energetics of human activity. Champaign: Human Kinetics, 2000:66-95.

71. Davison RCR, Grant S. Is walking sufficient exercise for health? Sports Med 1993;16:369-73.

72. Morris JN, Hardman AE. Walking to health. Sports Med 1997;23:30632.

73. Monteiro WD, Silva SC, Araújo CGS. Diferenças nas respostas cardiorrespiratórias obtidas na caminhada e na corrida em velocidades padronizadas: estudo piloto [resumo]. Anais do XXIII Simpósio Internacional de Ciências do Esporte 2000:94. 